\title{
Flights of Fantasy? Or Space-Time Compression in Asian-Australian Picture Books
}

\author{
Trish Lunt
}

\begin{abstract}
Metaphors of hybridity and the like not only recognize difference within the subject, fracturing and complicating holistic notions of identity, but also address connections between subjects by recognizing affiliations, cross-pollinations, echoes and repetitions, thereby unseating difference from a position of absolute privilege...such metaphors allow us to conceive of multiple, interconnecting axes of affiliation and differentiation.
\end{abstract}

(Felski 1997, p.12)

While the concepts of space and time affect people universally, they occupy a dominant position in childhood experience by virtue of their fluidity. For a growing body that is rapidly being redefined in space as clothes, furniture and developmental phases are outgrown at what seems to surrounding adults to be an exponential rate, but that often feels to the child waiting for the next long-off birthday to be agonisingly slow. Thus, space and time are understood experientially in complex but often unexamined ways. This fluidity of space and time is likewise central to but also often uncritically recognised in the representational spaces of the picture books that children consume. In order to engage with the conceptual, semiotic and socio-political dimensions of the space-time continuum in picture books, this paper will assess two stories that negotiate physical and psychical depictions of migration. The analysis will proceed by looking at the ways in which hybridised space operates as a function of power and subjectivity central to the project of mediating narratives about Asian-Australian diasporic cultures. My analysis here relates only to textual representations of migrant experience, rather than judgements about identity politics per se; and suggests ways in which diasporic experiences are negotiated across space and time in picture books.

Diversions from the Western rationalist conception of space-time have provided fertile ground for fictional adventures into alternate time-spaces of the literary imaginary. Time- and space-shift adventures have a long history in fantasy children's literature, but little attention has been paid to the 'fantasy moment' set within the realist narratives in contemporary Australian picture books about migrant experiences. By affording specific attention to the operations of space in Australian picture books for children we can draw connections between the ways in which spatial relations direct power shifts in pictorial texts, and inform constructions of cross-cultural identity as both the fantasy and reality of hybrid cultural experience. Diasporic texts in particular adopt narrative mechanisms that, while reflecting the fantasy genre, engage with a multicultural construction of space-time that disrupts conventional Western schematics and displaces hegemonic notions of being and belonging that is extended rather than limited by perceptions of space and time. As an outcome of my assessment of two picture books, using them as case-studies for spatiality as a mechanism for engaging child readers with migration logics, I will go on to propose a model of analysis that collapses space and time through the critical application of Harvey's $(1990,1996)$ conception of spatiality as relational flow and Deleuze's (1993) configuration of Le Pli (the Fold).

Textual representations of Australian migrant populations have shifted markedly from the 1940 s to the present. The trajectory includes a sustained period of textual engagement with European immigration - in novels, school readers, picture books, filmic texts - that focused on the emplacement of Greek and Italian migrant families within an assimilated Australian context. More recently, there has been a focus on the experience of migration from Asia to Australia (and one might ponder the reasons for this: a cultural shift in literary production that displaces a white cultural hegemony; or a requirement for publishing directed towards a marketable cultural sector; or both and more). While these more recent texts often deal with assimilationist ideals, they exhibit strong codings of multiple cultural identities that are complex in both their spatial schematics - for example, notions of belonging to place, here/there and home/away dichotomies - and in their construction of hybridized identities.

Laaksonen states that 'in our globalized world culture is becoming a hybrid and fluid mixture of global and local multiplicities and spaces or scales. We just need to discover and recognize those specific hybrids of discourses, spaces of culture'(Laaksonen 2005). As cultures merge, hybrid spaces appear and dislocate national securities of spatial presence and scalar models of conceiving the world. The texts selected for discussion provide one means for representing 
those spaces and analysis of them answers Laaksonen's call by providing a way to recognize overlapping, blending and/or assimilations of 'culture' as itself a space in which migrant subjects are situated in order to understand their place(s) in the physical and metaphysical world they tread. So, flights of fantasy; or space-time compression in AsianAustralian picture books?

The portmanteau term 'Asian-Australian' is problematic, as Jacqueline Lo says, for its capacity to homogenise and essentialise (Lo 2000, p.153). I would add to that terminological predicament the acknowledgement that both of the cultural identifiers, 'Asian' and 'Australian', belong to a Western Imperialist-Orientalist discourse of belonging and not-belonging to nation-state. However, when the focus is placed on the hyphen, and not on the cultural branding, the term Asian-Australian invites a hybridized conception of belonging that exists outside the nation-state and the global political imaginary. In her studies ofChinese-Australian diaspora, Ien Ang acknowledges that 'how differently positioned subjects can make themselves understood and construct shared understandings across cultural boundaries...is a central [problematic] for social life in our increasingly multicultural world, both nationally and globally' (Ang 2001, pp.166-167). In deconstructing the space of the hyphen, and considering how cultural interstices are configured in picture books about crosscultural experience, cultural space reveals itself as unbordered and fluid, thus challenging the spatial stasis of nationalist identity. Cultural identity is not bound by national borders, nor homogenised by globalisation.

In this sense the hyphen is more than a grammatical marker for the hybrid term, Asian-Australian; it can also be understood as a functioning metaphor for the visual images which, in their hybrid nature, stretch between the poles of nation. Images can function like a language when certain styles of representation recognizably belong to a cultural tradition, for example, Pitjantjatjara traditional artworks, but in the realm of contemporary children's picture book publishing images do not usually require the kind of acts of translation that a story written in another language would necessitate. Taking this somewhat oversimplified claim about the visual codes in picture books as given (keeping in mind that the simplification is designed to allow an uninterrupted focus on the image-language), the texts I have selected for discussion play in the region of the hyphen. They invoke a collapse of space and time that provides a hyphenated meeting-space for cultural liaison.

The Year of Pink Pieces by Errol Broome and Lee Smith (1987) depicts (in a mostly trite and superficial way) the ongoing connection between two boys, Yoshito and Ben after Yoshito and his family return 'home to Japan' after an unspecified residence in Australia. The cultural content in the book relies on a clichéd iconography of difference: Yoshito will miss eating meat pies and Ben will crave Mrs Murata's onigiri, and retains his partiality for seaweed and rice balls instead of chips and peanuts. The flags of Japan and Australia, and motifs of Uluru and Mount Fuji, sit adjacently as political and cultural representatives of individuated nationhood. As a purely literary device, the Murata family departs Australia by ship (at a time when the bmx bike and orange ergonomic chair speak specifically of the 1980s) in a gesture which recruits a temporal overcoding on the spatial separation of the boys' 'home' countries. That is, the text relies on archaic metaphors to emphasise the physical distance that the boys endure.

The departure by ship enables, however, the use of the metaphorical device of the streamer, half of which is retained by each boy as a sign of their coexisting separation and connection. The streamer breaks and Ben retains it. Each week Ben mails a fragment of it to Yoshito who, 'over a year', tapes them together and attaches the reconstructed streamer to the motif-laden kite which, he says, needs a very long tail to 'reach across the world' to Australia. The fantasy element of the text comes into play as the kite makes its way to Australia, collects a pyjama-clad Ben, and carries him to Yoshito's balcony in Japan. As dawn arrives, Ben returns home on the kite, with the 'long pink tail wav[ing] like a streamer that had never been broken'. The cultural distinctions held in place by binarised motifs are preserved by the spatial conditions of home and away, here and there, departure and return. The distance over time equation is marked according to the Western calendar that divides the streamer into the fifty-two weeks of a year in measured and clinical ways. This anniversary of their separation is arguably then an emotional marker with the potential to overcome loss when 'time heals all wounds'. In this way the 
story intersects emotional, cultural and physical journeys of separation but resolves on a fantasy of reconnection itself as fragile as a dismembered streamer held together in fifty-two places with tape. That this object can survive the journey from Australia to Japan and back again is the fantasy within the fantasy motif of the story (a dream interlude set in the realist narrative) and functions to suggest both the necessity for imaginative spaces of connection but also their impossibility. In the positivist vein of many children's texts such fantasies allow if not happiness at least comfort to prevail such that the space-time continuum holds together in dream-space as a form of resistance to the realities of geographic and temporal distance.

Old Magic by Allan Baillie and Di Wu (1996), on the other hand, depicts a journey towards knowledge across time. Omar, bearing the paraphernalia of the 1990s Australian child - basketball, skateboard, walkman - meets his grandfather, Kakek, outside a suburban Californian bungalow with its obligatory hills hoist. The kakek's spinning top calls up mystical images of timeless Indonesian myth. As Bradford (2007) explains, 'kakek' has dual meaning, both in terms of describing the familial and cultural relativities of the relationship between these two characters. Kakek, as used in this text, means not only grandfather, but astute cultural elder and mystic; both roles are played by the same character, who is central to the complex of cultural identities within the text. When the kakek leaves the top, Omar envisions Indonesion mythical stories, and remembers life 'in the village' before his family migrated to Australia. Motivated by memories of the 'good things' in the past (both recent and historical cultural knowledge), he constructs a kite for his grandfather. His gift to Kakek is not the dragon kite, but Omar's reconnection with cultural history, both short- and long-term. Omar connects not only with his grandfather in the space of contemporary migratory relocation, but with the cultural history of diasporic ethnicity.

These books adopt the apparatus of fantasy to represent diasporic experience at a metaphorical level. The dream-like conflation of space-time constructs a hyphenated diasporic subjectivity which, as explained by Lo, 'emphasises identity formation as a provisional and fluid process [that] unsettles dominant expectations of the unproblematic homology between cultural, racial and national identity' (Lo 2000, p.156). In this case, fantasy functions as the arbiter of fluidity, hybridity and in-between-ness, closing the gap between the here and there, now and then.

The condition of in-between-ness is demonstrated in these texts not only by the mechanics of cultural encounter where home is a contested space that traverses multiple spatial and temporal realms of cultural identity, but also by the production of spatial relations on the page. As social geographer, David Harvey, explains, 'the production of spatial relations... is a production of social relations' (Harvey 1996,p.112). Each of these texts begins by making strong binary distinctions between peoples and places, with signifying markers of identity based firmly in nation-state iconography. However, readings against the iconic grain of the texts disclose the concurrent production of hybrid, or hyphenated, formations of enculturated subjectivity and power that are played out in the relational positioning of characters, objects and scenes. An analysis of social relations, at macro- and micro-spatial scales in these stories demonstrates the ways in which texts work in multiple conceptual fields in the single space-time between the covers of the picture book itself.

In the first doublespread of Old Magic, Kakek and Omar are situated antagonistically, separated by the middle of the page. If the double-spread is quartered, however, power relationships operating at an affective level in the text become easier to identify. Omar is positioned at the top of the page, which can be read as sign of his dominance. The relative abundance of cultural detail around him implies the importance of assimilation and the adoption of dominant codes in performing culture. In comparison, the kakek's positioning in a white void, and the fact that neither looks at the other, suggest Omar's rejection of ethnic traditions.

At the same time, other spatial processes are operating in this illustration that compete with the sense of power invested in the figure of the Australianised child. The replication of colour in the clothing draws the gaze into a line of connectedness between the two figures. The energy emanating from the top creates a line offlow in the narrative, uniting the presence of the figures and leading them in the 
same direction - off the page to the left. This suggests, in the mechanics of the picture book, a journeying backwards, into the past. If we take into consideration the positioning of the kakek on the right of the double spread and the boy on the left, conventional western reading practices focus the gaze on the kakek prior to shifting across the page to Omar. This down-up, right-left direction of the gaze usurps the power invested in the top-down spatial empowerment of Omar and reconfigures power in the kakek. It is the kakek, after all, who motivates Omar to develop a connectedness with his Chinese-Indonesian culture.

In the subsequent doublespread, the positioning of the characters is reversed, shifting the spatialised power relationship between the two figures and investing power in the child's tentative engagement with his grandfather's mission. The illustrations on the following pages return the kakek to the right of the scene, drawing Omar, and the implied reader with a left-to-right gaze, further into his powerful role as arbiter of cultural knowledge. The kakek, his top, and the emanating trace of cultural connection lead Omar towards a hybrid time-space in which both his Australian and Indonesian cultures mingle in a fluid state, symbolized in the end by the kite which carries multiple identity constructions at the liminal border of Australian nationhood - the beach.

The top's energy generates delicate, ephemeral traces of space-time connection; the cultural time-shift narrative which explores a mythical and ever-present past is carried visually and spatially by this fluid, umbilical, contouring of multiple presents/presences. The profusion of detail in Omar's memory of his village prior to migration suggests an accompanying lack in cultural significance in his new Australian home, displacing the initial prominence of the garden and clothesline, skateboard, walkman, dried earth and muted colours with the strong, fertile, sensory greens and blues of myth and memory. In connecting these times and places, the top and its twine embody the hybrid connection as the trace, the spatial manifestation of the semiotic hyphen; it is the connective flow.

In A Year of Pink Pieces, the positioning of the boys shifts to depict their separation and, alternatively, their closeness. Distancing is a spatial function of the plot, which begins and ends with the focus on Ben's experience of leave-taking. Ben is the protagonist of this story, since Yoshito leaves Ben's (national and notional) space. But Ben is subject to the loss that Yoshito causes, such that the departing migrant is, in a strange power reversal, agential. As child subjects, both boys are also relatively powerless in the landscape of adult decision-making in ways that level the playing field of a relationship based on playing together. However, the half-page vertical split - when Ben puts his streamer in his pocket and Yoshito puts his into a box provides equal space for the boys, and at the same time, signifies the distance that sits between them. The framing of this page reinforces the spatialised gap that separates them, and the containers the boys respectively use to store the marker of their separation rely on fixed boundaries to enclose (and potentially make less threatening) the symbol of their disconnection and loss.

Laaksonen's conception of multiple scales can be seen operating in the way that the gap functions as a space in itself, so that there are three spatial frames on the page - Ben's space, Yoshito's space, and the space between them. At the same time, however, the positioning of both boys on the same page replicates their closeness in other illustrations, such as when they sit under the tree eating pies, and indicates their proximity despite the distance that divides them. There are more than three spaces in the page, then. The spaces multiply according to perspectival scales, and function as an interconnected field of fluid spatiality and overlapping sites of multiply extant states of being.

The spatial relations in these texts shift and turn in a wave of disconnection and connection, divergence and convergence. They do not proceed as momentary glimpses at a linear sequence of events. While at the surface, the stories progress in a linear manner, the implication of multiple spatial readings is that many different things are happening in the same time or place. Further, both texts employ a source of connection across the space-time gap that is, they take up the motif of the streamer that stabilizes a kite, a cord and energy flow that sends the top spinning as key metaphors for unbroken associations regardless of physical and/or temporal distancing. This metaphor can be conceived more generally in the form of the ribbon. The ribbon characterises the essence of movement-in-stasis. 
Spatial flow is the grounding for Harvey's dialectical and relational model of spatiality. According to Harvey, space and place are not inert and immobile objects but relational processes configured by cultural constructions which include the physical (landscape, architecture), the personal (feelings, emotions, subjectivities), and the imaginary (media, representation, fiction). Harvey contends that time and space are contiguous, and that 'everything can be reduced to flows'(Harvey 1996, p.8). Flow theory provides the wave function that links Lefebvre's 'lived', 'perceived' and 'conceived' space(s) (1991). The application of flow theory connects spaces that may otherwise be considered disconnected. The streamer in The Year of Pink Pieces, for example, not only provides Ben with the opportunity to meet again with Yoshito, it scaffolds the persistent flow of connectedness. The ribbon-flow closes the gap: it extends beyond the frame of the illustrations, always in flight, sustaining the relationship between the boys albeit in fragile and wind-blown uncertainties. It operates, also, as the omnipresent conduit between the boys and their cultures. It is an open conduit that collapses the boundaries of Western conventions of space and time, challenges the borders of the nation-state as the receptacle of cultural identity.

The boys' pink streamer and the cord with which Kakek spins his top (and their consequent traces of energy and connection) take the form of the wave. There are no straight lines in a wave; it is a series of undulations, turning, spinning, winding, contesting linear functions. For Harvey, the concept of time-space compression signals "processes that so revolutionize the objective qualities of space and time that we are forced to alter, sometimes in quite radical ways, how we represent the world to ourselves" (Harvey 1990, p. 240). While this compression of time and space is sustained by flow mechanics, as explained above, these picture books conceive a simultaneous spatial process that operates within the wave function. This is the fold.

Deleuze (1993) conceived the fold (le pli) as the portal between two floors in Baroque architecture, by which, through flow and flux, the two floors (or worlds) fold into each other. The same architectural intervention in space is demonstrated in Old Magic by the quartering of the page, where four individuated spaces are identified as interconnected in the one space, a function of scale and narrative overlay that produces multiple overlaid points of reference and meaning. The folding of the ribbon (or its pattern as depicted by the top's flow of energy, the meandering of the streamer, and the flight path of the kite) provides a deviation from linearity so that multiple events occur in the same space-time, the past is invited into the present, and intimate connections are made across spatial and temporal gaps. Whereas flow functions to close the gaps, the fold operates against singularities and opens up multiplicities (or lines of flight) of interpretation, action and connectedness. It is in the interstitial space of the gap (at the hyphen), that the ribbon motif operates - as a long and fluid hyphen. The flow/flux/fold of the ribbon makes the connection between worlds conceived otherwise as separate and distinct. Therefore, it is possible to conceive the ways in which diasporic connections transcend space and time. Personal connections challenge the boundaries of the nation-state and temporalised cultural histories. Cross-cultural connections co-exist in a fluid space-time that navigates the arbitrary stasis of cultural boundaries.

A spatial reading of these texts, then, which takes into consideration positionings, flows and folds, provides a method for interpreting the negotiations of space, place and identity in the global passage of peoples and cultures. What eventuates from this compression of cultural spacetime is a 'third space' (Bhabha 1998; Soja 1989) which is not merely a connection between the past and the present or of personal relationship, but a reterritorialisation that depicts not two worlds, but three, or more - as a result of the negotiated connections between the others: 'a new part fabricated separately' (Deleuze and Guattari 1983, p.42). Multiple sites of presence that cross geographical and generational borders fluidly transgress the Western paradigm of a sustained separation between time and space. These texts thereby invite the implied reader into a liminal realm where intersecting lines of flight offer multiple textual interpretations and alternative views of the world beyond the binarised and bounded logic of Imperialist discourses.

This is not to say that fluidity always transpires as a gentle osmotic cross-permeation. Arjun Appadurai (2006) admits that fluidity unsettles. Diasporic connections are affected by ideological constructions of the nation-state and hegemonic 
identity politics; cross-culturalism is not necessarily a comfortable hybridity. The acknowledgement of multiple registers and negotiations (and renegotiations) of space, place, identity and power relations, however, opens up a space of networks of power and subjectivity that displace hegemonically-coded theoretical positionings of us-them, here-there, global-local, home-away, and invite us to play in the space of the altogether and in-between, in the space of the hyphen that both connects things and separates them at the same time. And, as children playing know, time flies when you're having fun.

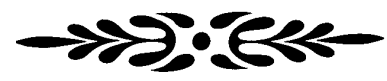

\section{REFERENCES}

Ang, Ien (2001) On Not Speaking Chinese: Living Between Asia and the West. London, Routledge.

Appadurai, Arjun (2006) Fear of Small Numbers: An Essay on the Geography of Anger. Durham, Duke University Press.

Baillie, Allan and Wu, Di (1996) Old Magic. Milsons Point, NSW, Random House.

Bhabha, Homi K. (1998) 'Culture’s in-between' in Stuart Hall and Paul du Gay (eds), Questions of Cultural Identity. London, Sage, pp.52-60.

Bradford, Clare (2007) 'Cross-generational negotiations: Asian Australian picture books', Papers: Explorations into Children's Literature, 17, 2, 36-42.

Broome, Errol and Smith, Lee (1987) A Year of Pink Pieces. Melbourne, Interbac.

Deleuze, Gilles and Guattari, Félix (1984) Anti-Oedipus: Capitalism and Schizophrenia, trans. R. Hurley, M. Seem and H.R. Lane. London, Athlone.

Deleuze, Gilles and Guattari, Félix (1987) A Thousand Plateaus: Capitalism and Schizophrenia, trans. B Massumi. Minneapolis, University of Minnesota Press.

Deleuze, Gilles (1993) The Fold: Leibniz and the Baroque, trans. T. Conley. London, Athlone.
Felski, Rita (1997) 'The doxa of difference', Signs 23, 1, 1-22.

Harvey, David (1990) The Condition of Postmodernity: An Enquiry into the Origins of Cultural Change. Cambridge, Blackwell.

Harvey, David (1996) Justice, Nature and the Geography of Difference. Cambridge, Blackwell.

Laaksonen, Tarja-Liisa (2005) 'Liberal "organisational culture" discourses in time, space and agency context'. <http://www.transforma-online.de/ english/transforma2005/ papers/laaksonen.html> [viewed 6 July 2008]

Lefebvre, Henri (1991) Critique of Everyday Life, trans. J. Moore. London, Verso.

Lo, Jacqueline (2000) 'Beyond happy hybridity: performing Asian-Australian identities', in I. Ang, S. Chalmers, L. Law and M. Thomas (eds) Alter/Asians: Asian-Australian Identities in Art, Media and Popular Culture. Annandale, NSW, Pluto Press, pp.152-168.

Soja, Edward (1989) Postmodern Geographies: The Reassertion of Space in Critical Social Theory. London, Verso.

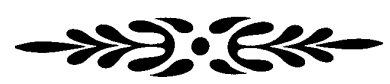

\section{BIOGRAPHICAL NOTE}

Trish Lunt (MA) is currently engaged in doctoral research investigating the spatial construction of power and subjectivity in contemporary Australian picture books with refugee, migrant and Indigenous Australian protagonists. Her focus is cross-disciplinary, drawing on literary and cultural studies, geographies, architecture, physics and phenomenology in ways that recognise spatiality as a key textual conduit in the communication and reception of meaning(s). She teaches children's literature at Deakin University and is a member of ACLAR and IRSCL. 